\title{
EFEITO DO FATOR DE CONCENTRAÇÃO DO RETENTADO NA COMPOSIÇÃO E PROTEÓLISE DE QUEIJO MINAS FRESCAL DE BAIXO TEOR DE GORDURA FABRICADO POR ULTRAFILTRAÇÃO ${ }^{1}$
}

\author{
Clarissa Reschke da CUNHA²; Leila Maria SPADOTI²; Patrícia Blumer ZACARCHENCO²;
}

Walkíria Hanada VIOTTO ${ }^{2, *}$

\section{RESUMO}

O efeito da concentração do leite por ultrafiltração na composição e proteólise do queijo Minas Frescal de baixo teor de gordura durante o armazenamento refrigerado foi determinado. Três bateladas de queijo foram processadas em um dia, usando leite ultrafiltrado a três diferentes fatores de concentração (FC): 2:1, 3:1 e 4:1. A fabricação dos queijos foi realizada em duplicata. A evolução da proteólise foi acompanhada através da determinação do $\mathrm{pH}$, acidez titulável e índices de proteólise nos dias 2, 10, 20 e 30 após a fabricação. Os fatores de concentração testados não afetaram significativamente a composição e a proteólise do queijo. Para todos os queijos, o pH diminuiu com o tempo, enquanto a acidez e os índices de extensão e profundidade de proteólise aumentaram. Portanto, a inclusão de proteínas do soro pela ultrafiltração não inibiu a ação proteolítica do coagulante. Para a faixa de FC estudada, os efeitos negativos associados ao aumento do teor de umidade dos queijos (maior intensidade de glicólise e proteólise e maior suscetibilidade a microrganismos contaminantes) predominaram sobre as potenciais vantagens tecnológicas do uso da técnica de ultrafiltração. Em função disso, observou-se uma tendência de diminuição da vida útil desses queijos, em relação aos queijos fabricados pelo método tradicional.

Palavras-chave: queijo Minas Frescal; tecnologia de membranas; produto "light"; proteólise.

\section{SUMMARY}

EFFECT OF RETENTATE CONCENTRATION FACTOR IN THE COMPOSITION AND PROTEOLYSIS OF LOW FAT 'MINAS FRESCAL' CHEESE MADE BY ULTRAFILTRATION. The effect of milk concentration by ultrafiltration on the chemical composition and proteolysis of low fat Minas Frescal cheese during refrigerated storage was determined. Three batches of cheese were made in one day using milk concentrated by ultrafiltration at three different concentration factors $(\mathrm{CF}): 2: 1,3: 1$ and 4:1. Cheese making was replicated on a different day. Protein breakdown, as well as $\mathrm{pH}$ and titratable acidity changes, were monitored during cheese storage for 2, 10, 20 and 30 days. It was observed that $\mathrm{pH}$ decreased with time, while titratable acidity and protein breakdown increased. The different concentration factors tested did not significantly change cheese composition and proteolysis, which means that the inclusion of whey proteins did not inhibit rennet proteolytic activity as expected. This leads us to believe that potential advantages associated with the use of ultrafiltration retentates in cheesemaking were compensated by negative effects related to the high humidity level of low fat cheese made from ultrafiltration retentates. Consequently, the shelf-life of this typically Brazilian cheese was lower than that of cheese made by conventional procedures.

Keywords: fresh cheese; membrane technology; light food; proteolysis.

\section{1 - INTRODUÇÃO}

Queijos com baixo teor de gordura se caracterizam por apresentar rendimento menor, textura mais dura e problemas de acidez e sabor amargo quando comparados aos queijos tradicionais [5, 13].

A técnica de ultrafiltração representa uma das melhores alternativas para aumentar o rendimento e melhorar a textura e o sabor de queijos produzidos a partir de leite desnatado em relação aos queijos fabricados pelo método convencional [13]. A melhoria da qualidade do queijo ocorre fundamentalmente em função do decréscimo do teor de lactose, o que resulta em um maior controle da taxa de acidificação, e da incorporação de proteínas do soro, que aumentam a capacidade de retenção de água do queijo, tornando-o mais macio [16]. Além disso, as proteínas do soro não desnaturadas são mais resistentes à ação proteolítica de enzimas do coalho e da cultura láctica, o que previne a formação de peptídeos pequenos e hidrofóbicos responsáveis pelo desenvolvimento de sabor amargo [12].

A incorporação das soroproteínas afeta, ainda, a proteólise primária. A quebra da caseína diminui com o aumento do fator de concentração, em virtude de interações entre as proteínas do soro e enzimas proteolíticas, especialmente a inibição do coalho e da plasmina pela $\beta$-lactoglobulina [3].

Em queijos não maturados, como o Minas Frescal, os efeitos de diminuição da intensidade da proteólise e de prevenção da acidificação excessiva, promovidos pela ultrafiltração, podem ser encarados como uma vantagem, uma vez que contribuem para um potencial aumento da vida útil do produto.

No presente trabalho, foi testado o efeito do uso de leites concentrados a diferentes fatores de concentração $(2: 1,3: 1,4: 1)$ sobre a proteólise do queijo Minas Frescal.

\section{2 - MATERIAL E MÉTODOS}

\subsection{Ultrafiltração do leite}

Leite desnatado pasteurizado, proveniente da Cooperativa dos Produtores de Leite de Campinas (CPLC), foi aquecido a $55^{\circ} \mathrm{C}$ e posteriormente concentrado, por ultrafiltração, em sistema dotado de membrana "hollow

${ }^{1}$ Recebido para publicação em 01/06/01. Aceito para publicação em 12/11/01.

${ }^{2}$ Faculdade de Engenharia de Alimentos, Universidade Estadual de Campinas-UNICAMP. CEP 13083-970-Campinas-SP, Brasil. E-mail: walkiria@fea.unicamp.br

* A quem a correspondência deve ser enviada. 
fiber" de polissulfona, marca Romicon $\AA$, com peso molecular de corte de 10.000Daltons, área superficial de $1,4 \mathrm{~m}^{2}$, pressão transmembrana de $1,5 \mathrm{kgf} / \mathrm{cm}^{2}$, até obtenção de retentado com $\mathrm{FC}$ igual a 4:1. A partir deste retentado, foram feitas diluições, através da adição de permeado, para a obtenção dos retentados com FC 3:1 e $2: 1$.

O fator de concentração (FC) foi calculado conforme a equação abaixo:

$$
\mathrm{FC}=\frac{\text { massa de leite }(\mathrm{kg})}{\text { massa de leite }(\mathrm{kg})-\text { massa de permeado }(\mathrm{kg})}
$$

Esse cálculo, no entanto, está sujeito a uma série de erros, em virtude da dificuldade de determinar a quantidade exata de permeado. Portanto, o FC foi recalculado com base no fator de concentração da gordura, dado por:

$\mathrm{FC}=\frac{\text { Teor de gordura no retentado }(\%)}{\text { Teor de gordura no leite }(\%)}$

uma vez que a gordura é o único componente do leite totalmente retido pela membrana, ou seja, apresenta um coeficiente de retenção de 100\%.

\subsection{Fabricação do queijo}

Leites concentrados a FC 2:1, 3:1 e 4:1 foram resfriados a $32^{\circ} \mathrm{C}$ e transferidos para os tanques de fabricação. A cada tanque, adicionou-se 0,025\% de ácido lático em relação a quantidade de leite inicial (16 litros). O ácido láctico concentrado a $85 \%$ (marca Chemco) foi previamente diluído em água destilada a $2,5 \%$, para prevenir a precipitação de proteína. Para a coagulação, foi utilizado coalho bovino Bela Vista ${ }^{\circledR}$, da Fábrica de Coalhos e Coagulantes Bela Vista Produtos Enzimáticos Indústria e Comércio Ltda., em quantidade suficiente para coagular 16 litros de leite em 40 minutos.

A coagulação dos retentados ocorreu em 10 minutos. Ao final deste intervalo de tempo, a massa foi cortada em cubos de cerca de $1,5 \mathrm{~cm}$ de diâmetro e procedeuse a mexedura, durante 30 minutos. Em seguida, foram realizadas as etapas de dessoragem, salga na massa (adição de $2 \%$ de sal, marca Cisne $\left.{ }^{\circledR}\right)$ e enformagem. Os queijos foram deixados nas formas por $1 \mathrm{~h}$, sendo então embalados em potes plásticos de 500 g, e pesados. Para cada tratamento foram conduzidas duas repetições.

\subsection{Composição química}

Foram determinados o $\mathrm{pH}$, pelo método potenciométrico, e a acidez titulável do leite desnatado, dos retentados e dos queijos [15]. Os teores de sólidos totais do leite desnatado, dos retentados e dos queijos foram determinados gravimetricamente, em estufa de circulação forçada, a $100^{\circ} \mathrm{C}$ por 24 horas, segundo o método AOAC 925.23 [1]. A porcentagem de cinzas para as amostras de queijo e leite foi determinada por incineração em mufla a $550^{\circ} \mathrm{C}$, conforme o método AOAC 935.42
[1]. Para a quantificação da gordura nas amostras de leite, retentado e queijo foi utilizado o método de extração etérea de Monjonnier, segundo AOAC 989.05 [1]. Os teores de nitrogênio total [10], nitrogênio não caséico [2] e nitrogênio não protéico AOAC 991.21 [1] foram determinados pelo método de Kjeldahl, sendo os valores de nitrogênio multiplicados por 6,38 para obtenção dos valores equivalentes de proteína. O teor de sal do queijo foi determinado pelo método de Volhard [17]. Todas as análises foram realizadas em triplicata.

\subsection{Proteólise}

Extensão de Proteólise: A extensão de proteólise foi expressa como porcentagem do teor de nitrogênio total, segundo a equação 3 :

Extensão $=\underline{(\% \text { nitrogênio solúvel a } \mathrm{pH} 4,6) \times 100}$ \% nitrogênio total

Profundidade de Proteólise: A profundidade de proteólise foi expressa como porcentagem do teor de nitrogênio total, de acordo com a equação 4:

Profundidade $=(\%$ nitrogênio solúvel em TCA $12 \%) \times 100$

$$
\% \text { nitrogênio total }
$$

onde: TCA = ácido tricloroacético.

\subsection{Planejamento experimental e análise estatística dos resultados}

O delineamento experimental foi do tipo aleatorizado em blocos. O fator estudado foi o fator de concentração do leite (T), nos níveis 2:1, 3:1 e 4:1. Esses três tratamentos foram realizados em duplicata.

Os resultados foram analisados através de Análise de Variância (ANOVA), utilizando-se o teste de Tukey para verificar diferenças entre as médias.

Para a avaliação do $\mathrm{pH}$, da acidez e da proteólise, foi adotado um delineamento do tipo split-splot, sendo que a sub-parcela foi obtida pela incorporação do fator tempo de armazenamento refrigerado (t). As análises de $\mathrm{pH}$, acidez e proteólise foram realizadas nos dias 2, 10, 20 e 30 de armazenamento refrigerado.

O teste de F-ANOVA foi usado para avaliar as diferenças entre tratamentos, entre tempos e a interação tempo versus tratamento. Foi utilizado o teste de Tukey de comparações múltiplas para agrupar tratamentos e/ ou tempos com médias cujas diferenças não foram estatisticamente significativas.

\section{3 - RESULTADOS E DISCUSSÃO}

\subsection{Composição química}

\subsubsection{Composição do leite}

Os valores de sólidos totais, gordura, proteína, cinzas, $\mathrm{pH}$ e acidez, relativos aos leites utilizados na obtenção dos retentados 2:1, 3:1 e 4:1, são apresentados na Tabela 1. 


\subsubsection{Composição dos retentados}

Os valores de sólidos totais, gordura, proteína, caseina, NNP, caseina/gordura, $\mathrm{pH}$ e acidez, relativos aos retentados utilizados na fabricação dos queijos, são apresentados na Tabela 2 .

TABELA 1. Média $(n=2)$ da composição do leite desnatado utilizado na obtenção dos retentados 2:1, 3:1 e 4:1

\begin{tabular}{lc}
\hline \multicolumn{1}{c}{ Componente } \\
\hline Extrato Seco Total - EST (\%) \\
Gordura (\%) & 8,76 \\
Proteína Total (\%) & 0,44 \\
Cinzas (\%) & 3,26 \\
$\mathrm{pH}$ & 0,66 \\
Acidez ( ${ }^{\circ}$ Dornic) & 6,69 \\
\hline
\end{tabular}

Os teores de NNP, caseína/gordura, pH e acidez dos diferentes retentados não apresentaram diferenças estatisticamente significativas $(p>0,05)$.

Os teores de gordura, sólidos totais, proteína e caseína dos retentados 2:1, 3:1 e 4:1 apresentaram tendência de aumento com o aumento do fator de concentração. Esse resultado já era esperado, uma vez que a membrana de ultrafiltração retém componentes de alto peso molecular, como proteína e gordura [9,11].

Em relação à acidez titulável, foi observada uma tendência de aumento com o aumento do FC. Esse aumento é função da incorporação de proteínas do soro, o que aumenta a acidez aparente dos retentados e resulta em aumento do poder tamponante [14]. O aumento da capacidade tampão é claramente evidenciado pelo fato de que, apesar da acidez aumentar com o aumento do FC, o $\mathrm{pH}$ permanece praticamente inalterado para todos os retentados, independente da concentração.

TABELA 2. Média $(n=2)$ da composição dos retentados usados na fabricação dos queijos

\begin{tabular}{lccc}
\hline \multicolumn{1}{c}{ Componente } & \multicolumn{3}{c}{ Retentados } \\
\cline { 2 - 4 } & $F C 2: 1$ & $F C 3: 1$ & $F C 4: 1$ \\
\hline $\operatorname{EST}^{1}(\%)$ & $14,28^{\mathrm{c}}$ & $18,65^{\mathrm{b}}$ & $23,15^{\mathrm{a}}$ \\
Gordura (\%) & $0,90^{\mathrm{a}}$ & $1,28^{\mathrm{a}}$ & $1,82^{\mathrm{a}}$ \\
Proteína (\%) & $8,23^{\mathrm{c}}$ & $11,94^{\mathrm{b}}$ & $15,92^{\mathrm{a}}$ \\
Caseína (\%) & $7,52^{\mathrm{c}}$ & $10,91^{\mathrm{b}}$ & $14,51^{\mathrm{a}}$ \\
$\mathrm{NNP}^{2}(\%)$ & $0,025^{\mathrm{a}}$ & $0,032^{\mathrm{a}}$ & $0,042^{\mathrm{a}}$ \\
$\mathrm{C}^{3}$ & $8,36^{\mathrm{a}}$ & $8,52^{\mathrm{a}}$ & $7,97^{\mathrm{a}}$ \\
$\mathrm{pH}^{\mathrm{A}}$ & $6,51^{\mathrm{a}}$ & $6,51^{\mathrm{a}}$ & $6,53^{\mathrm{a}}$ \\
Acidez ( ${ }^{\circ}$ Dornic) & $38,07^{\mathrm{a}}$ & $51,44^{\mathrm{a}}$ & $60,04^{\mathrm{a}}$ \\
\hline
\end{tabular}

${ }^{1}$ Extrato Seco Total

${ }^{2}$ Conteúdo de nitrogênio não-protéico

3elação caseina/gordura

Obs.: Médias com letras iguais, na mesma linha, não diferem significativamente entre si $(p>0,05)$

\subsubsection{Composição dos queijos}

Os valores de umidade, gordura, gordura em base seca, proteina, NNP, caseína, cinzas, sal, sal/umidade,
pH e acidez, relativos aos queijos obtidos a partir dos retentados 2:1, 3:1 e 4:1, são apresentados na Tabela 3. Os dados são referentes aos queijos após dois dias de fabricação.

Estatisticamente, não houve diferença significativa $(p>0,05)$ entre a composição dos diferentes queijos. Entretanto, pode ser observado que os teores de gordura e proteina tendem a aumentar com o aumento do fator de concentração.

Todos os queijos apresentaram teores de umidade e proteína superiores aos de um queijo Minas Frescal tradicional. O teor de umidade de um queijo Minas Frescal tradicional varia entre 55 e 58\% [7], enquanto o teor de proteína varia de 16 a $21 \%$ [19]. Esse resultado é função da incorporação de proteínas do soro pela ultrafiltração, o que aumentou a capacidade de retenção de água e diminuiu a dessoragem do queijo [16].

TABELA 3. Média $(n=2)$ da composição dos queijos obtidos a partir dos retentados FC2:1, FC3:1 e FC4:1 (após dois dias de fabricação)

\begin{tabular}{lccc}
\hline \multirow{2}{*}{ Componente } & \multicolumn{3}{c}{ Queijos } \\
\cline { 2 - 4 } & $F C 2: 1$ & $F C 3: 1$ & $F C 4: 1$ \\
\hline Umidade (\%) & $67,85^{\mathrm{a}}$ & $65,92^{\mathrm{a}}$ & $65,54^{\mathrm{a}}$ \\
Gordura (\%) & $2,72^{\mathrm{a}}$ & $2,83^{\mathrm{a}}$ & $3,00^{\mathrm{a}}$ \\
GBS $^{1}$ & $8,46^{\mathrm{a}}$ & $8,30^{\mathrm{a}}$ & $8,71^{\mathrm{a}}$ \\
Proteína (\%) & $22,05^{\mathrm{a}}$ & $23,92^{\mathrm{a}}$ & $24,01^{\mathrm{a}}$ \\
Caseína (\%) & $20,60^{\mathrm{a}}$ & $22,47^{\mathrm{a}}$ & $22,00^{\mathrm{a}}$ \\
NNP $^{2}(\%)$ & $0,094^{\mathrm{a}}$ & $0,114^{\mathrm{a}}$ & $0,144^{\mathrm{a}}$ \\
Cinzas (\%) & $3,42^{\mathrm{a}}$ & $4,03^{\mathrm{a}}$ & $3,94^{\mathrm{a}}$ \\
Sal (\%) & $1,40^{\mathrm{a}}$ & $1,54^{\mathrm{a}}$ & $1,35^{\mathrm{a}}$ \\
S/U & $2,06^{\mathrm{a}}$ & $2,34^{\mathrm{a}}$ & $2,06^{\mathrm{a}}$ \\
pH & $6,45^{\mathrm{a}}$ & $6,44^{\mathrm{a}}$ & $6,45^{\mathrm{a}}$ \\
Acidez (\% ácido láctico) & $0,16^{\mathrm{a}}$ & $0,17^{\mathrm{a}}$ & $0,17^{\mathrm{a}}$ \\
\hline
\end{tabular}

${ }^{1} \mathrm{GBS}=$ Gordura em base seca

${ }^{2} \mathrm{NNP}=$ Conteúdo de nitrogênio não-protéico

${ }^{3} \mathrm{~S} / \mathrm{U}=$ Relação sal/umidade

Obs.: Médias com letras iguais, na mesma linha, não diferem significativamente entre si $(p>0,05)$

\subsection{Evolução do pH e acidez}

A Tabela 4 apresenta a análise estatística da acidificação do queijo durante o armazenamento refrigerado $\left(6-7^{\circ} \mathrm{C}\right)$.

TABELA 4. Quadrado médio e probabilidades para valores de $\mathrm{pH}$ e acidez titulável do queijo durante os 30 dias de armazenamento refrigerado $\left(6-7^{\circ} \mathrm{C}\right)$

\begin{tabular}{llllll}
\hline \multicolumn{1}{c}{ Fatores } & \multicolumn{3}{c}{ Acidez Titulável } & \multicolumn{2}{c}{$\mathrm{pH}$} \\
\hline \multicolumn{1}{c}{$\mathrm{GL}$} & $\mathrm{QM}$ & $\mathrm{p}$ & $\mathrm{QM}$ & $\mathrm{p}$ \\
\hline Tratamentos $(\mathrm{T})$ & 2 & 0,000517 & 0,185 & 0,000904 & 0,420 \\
Erro(T) & 2 & 0,000117 & & 0,000654 & \\
Tempo (t) & 3 & 0,085522 & 0,000 & 0,040315 & 0,000 \\
Interação $(\mathrm{T} * \mathrm{t})$ & 6 & 0,001006 & 0,204 & 0,001915 & 0,306 \\
Erro(T*t) & 6 & 0,000494 & & 0,001243 & \\
\hline
\end{tabular}

$\mathrm{GL}=$ Graus de liberdade; $\mathrm{QM}=\mathrm{Quadrado}$ médio; $\mathrm{p}=$ Probabilidade

As Figuras 1 e 2 mostram, respectivamente, a evolução da acidez titulável e do $\mathrm{pH}$ durante os 30 dias de armazenamento refrigerado $\left(6-7^{\circ} \mathrm{C}\right)$. 
O fator de concentração não influenciou significativamente o $\mathrm{pH}(\mathrm{p}=0,420)$ e a acidez $(\mathrm{p}=0,185)$ dos queijos (Tabela 4). Por outro lado, tanto acidez como pH sofreram alterações estatisticamente significativas $(\mathrm{p}=0,000)$ com o tempo. Como pode ser observado na Figura 1, para todos os queijos a acidez titulável aumentou durante os 30 dias de armazenamento refrigerado. A evolução da acidez foi acompanhada pela redução correspondente do pH (Figura 2).

As variações de $\mathrm{pH}$ e acidez estão diretamente ligadas à degradação da lactose residual do queijo Minas Frescal. Como o queijo foi fabricado sem a adição de fermento láctico, a glicólise resultante deve ser resultado do crescimento da flora natural do leite resistente à pasteurização [18] ou de microrganismos contaminantes. Os valores de acidez nos 2 primeiros dias foram próximos aos encontrados por CAMPOS [4] para queijos Minas Frescal fabricados por acidificação direta, sem o uso de ultrafiltração (em torno de 0,15\% de ácido láctico). Já após o segundo dia de armazenamento refrigerado, o aumento da acidez titulável foi comparativamente maior que o observado por CAMPOS [4], e, após o dia 20, esse aumento foi ainda mais acentuado. No trabalho realizado por CAMPOS [4], a acidez aumentou de cerca de $0,15 \%$ de ácido láctico no segundo dia para cerca de 0,20\% no vigésimo-segundo dia. O resultado obtido em nosso experimento está provavelmente relacionado à atuação de microrganismos contaminantes, já que o maior teor de umidade dos queijos obtidos por ultrafiltração os torna mais suscetiveis à contaminação.

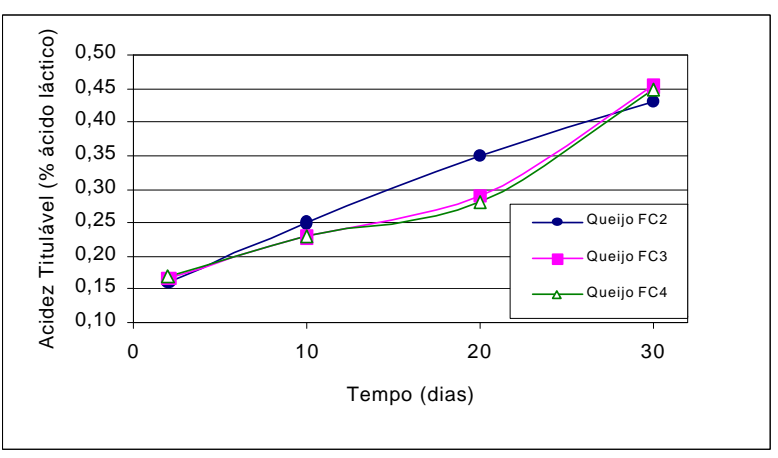

FIGURA 1. Evolução da acidez titulável durante a estocagem

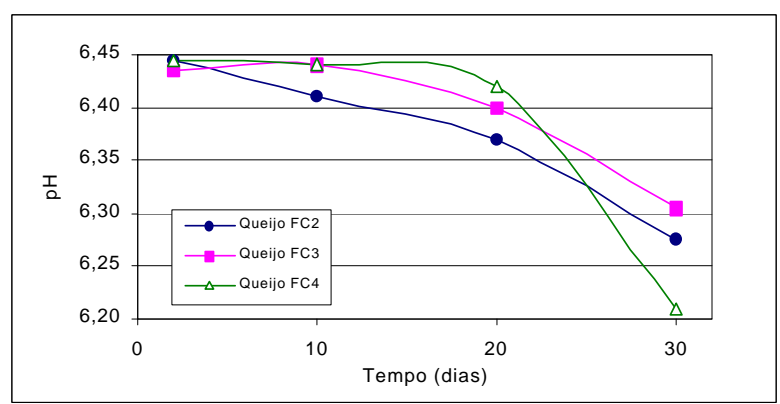

FIGURA 2. Evolução do pH durante a estocagem

Em relação ao $\mathrm{pH}$, os valores encontrados foram muito semelhantes aos encontrados por CAMPOS [4]. No tra- balho citado, o $\mathrm{pH}$ do queijo fabricado por acidificação direta variou de 6,4, no segundo dia, até cerca de 6,3, no vigésimo-segundo dia. Em nosso experimento, o $\mathrm{pH}$ diminuiu com o tempo, acompanhando o aumento da acidez titulável. Apenas nos últimos dias de armazenamento refrigerado a queda foi mais brusca, fato que também pode ser atribuído ao crescimento da flora contaminante.

\subsection{Evolução da proteólise}

A Tabela 5 apresenta a análise estatística dos niveis de proteólise do queijo com o tempo.

TABELA 5. Quadrado médio e probabilidades para os indices de proteólise dos queijos durante os 30 dias de armazenamento refrigerado

\begin{tabular}{llllll}
\hline \hline Fatores & \multicolumn{3}{c}{ NS $(\mathrm{pH} 4,6)$} & \multicolumn{2}{c}{ NS (TCA 12\%) } \\
\cline { 2 - 6 } $\mathrm{I}$ & $\mathrm{GL}$ & $\mathrm{QM}$ & $\mathrm{p}$ & $\mathrm{QM}$ & $\mathrm{p}$ \\
\hline \hline Tratamentos $(\mathrm{T})$ & 2 & 1,408 & 0,779 & 2,986 & 0,463 \\
Erro(T) & 2 & 4,969 & & 2,573 & \\
Tempo $(\mathrm{t})$ & 3 & 194,955 & 0,000 & 25,209 & 0,000 \\
Interação $\left(\mathrm{T}^{*} \mathrm{t}\right)$ & 6 & 1,184 & 0,199 & 0,259 & 0,725 \\
Erro $\left(\mathrm{T}^{*} \mathrm{t}\right)$ & 6 & 0,572 & & 0,432 & \\
\hline \hline
\end{tabular}

$\mathrm{GL}=\mathrm{Graus}$ de liberdade; $\mathrm{QM}=\mathrm{Quadrado}$ médio; $\mathrm{p}=$ Probabilidade

\subsubsection{Extensão da proteólise}

A extensão é um fator indicativo da proteólise primária. Teoricamente, a incorporação das soroproteínas afeta a proteólise primária da caseína, que tende a diminuir com o aumento do fator de concentração, em virtude da inibição do coalho e da plasmina pela $\beta$ lactoglobulina [3]. No entanto, diferenças no fator de concentração não influenciaram significativamente a extensão da proteólise do Minas Frescal ( $p=0,779)$, como pode ser observado na Tabela 5.

A evolução dos índices de extensão de proteólise dos queijos fabricados com diferentes fatores de concentração, durante os 30 dias de armazenamento refrigerado, é apresentada na Figura 3. Para todos os tratamentos, houve um aumento significativo nos indices de nitrogênio solúvel a $\mathrm{pH} 4,6$ (\%NS ( $\mathrm{pH} 4,6) / \mathrm{NT})$ com o tempo $(\mathrm{p}=0,000)$.

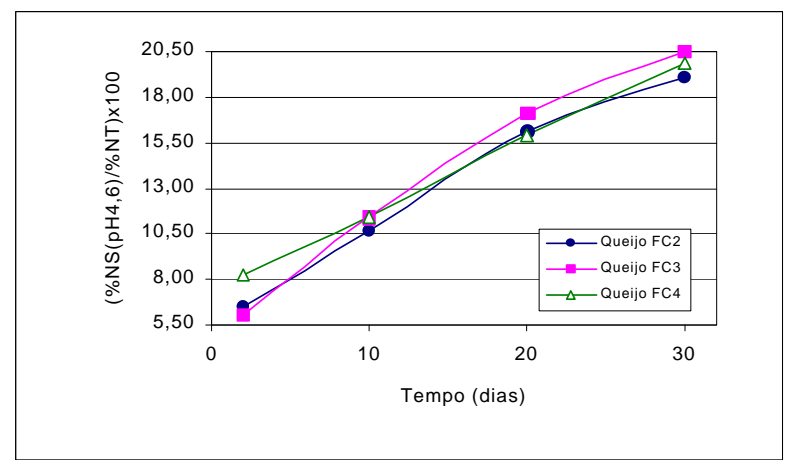

FIGURA 3. Evolução dos índices de extensão de proteólise durante a estocagem

Os altos niveis de nitrogênio solúvel a $\mathrm{pH}$ 4,6 encontrados devem estar relacionados à alta umidade dos 
queijos obtidos a partir dos retentados de ultrafiltração (em torno de 65\%). Maiores teores de água favorecem as reações enzimáticas, entre elas a ação hidrolítica da quimosina, que é o principal responsável pela proteólise primária no queijo Minas.

\subsubsection{Profundidade de proteólise}

A profundidade de proteólise está relacionada à presença de enzimas proteoliticas de microrganismos, que hidrolisam os peptídeos resultantes da ação do coalho e da plasmina sobre as caseínas [6]. Como os queijos foram fabricados sem a adição de fermento láctico, a proteólise secundária ocorre fundamentalmente em função da presença de microrganismos contaminantes ou resistentes à pasteurização.

A evolução dos índices de profundidade de proteólise durante a estocagem refrigerada é apresentada na Figura 4. Diferenças no fator de concentração não influenciaram a profundidade da proteólise $(p=0,463)$. Entretanto, para todos os tratamentos, houve um aumento significativo nos índices de profundidade de proteólise (\%NS(TCA $12 \%) / \mathrm{NT}$ ) com o tempo ( $\mathrm{p}=0,000)$, durante os 30 dias de armazenamento refrigerado. Esse aumento deve estar relacionado à atuação de enzimas provenientes de microrganismos contaminantes, que se desenvolveram em função do alto teor de umidade dos queijos. A alta umidade torna os queijos mais suscetíveis à contaminação [13]. De fato, foi observado o crescimento de bolores e leveduras nos queijos, em especial nos últimos 10 dias. Esses microrganismos podem ter liberado enzimas proteoliticas que, atuando junto com o coalho residual, aumentaram a intensidade da proteólise.

A alta atividade da flora contaminante pode estar relacionada, também, ao aumento da capacidade tampão dos queijos obtidos por ultrafiltração, que evita quedas acentuadas de $\mathrm{pH}$, mesmo quando o teor de ácido láctico é relativamente alto. Com isso, durante praticamente toda a vida-de-prateleira, o $\mathrm{pH}$ dos queijos permanece na faixa ótima para o desenvolvimento microbiano.

Comparando os valores do índice de profundidade de proteólise obtidos com os valores encontrados por CAMPOS [4] para queijo Minas Frescal fabricado por acidificação direta sem o uso da ultrafiltração, foi observado que o aumento na profundidade da proteólise ao longo do tempo foi muito mais acentuado nos queijos produzidos a partir dos concentrados de ultrafiltração. No trabalho citado, os valores do índice de profundidade de proteólise aumentaram de 1,2\%, no segundo dia, para cerca de 2,4\%, no vigésimo-segundo dia. Em nosso experimento, o aumento no índice de profundidade de proteólise, para todos os queijos, foi bem mais expressivo, como mostra a Figura 4.

FURTADO \& PARTRIDGE [8], trabalhando com queijos frescos, também encontraram valores maiores de extensão e profundidade de proteólise nos queijos fabricados a partir de retentados de ultrafiltração, em comparação com aqueles obtidos pelo processo tradicional.

Neste experimento, o alto teor de umidade dos queijos os torna mais suscetiveis à contaminação, favore- cendo a proteólise secundária. Em função do alto conteúdo de água, o esperado efeito de inibição da proteólise pelas soroproteínas ou a sua resistência à ação proteolítica do coalho foi suplantado(a) pela aceleração da proteólise.

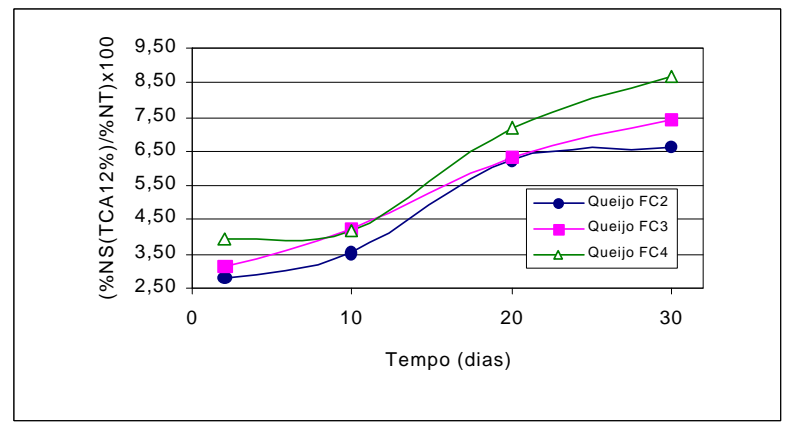

FIGURA 4. Evolução dos índices de profundidade de proteólise durante a estocagem

\section{4 - CONCLUSÕES}

O fator de concentração (FC) não afetou significativamente a acidez, o $\mathrm{pH}$ e a proteólise de queijos Minas Frescal produzidos a partir de retentados de ultrafiltração (UF) concentrados a FC 2:1, 3:1 e 4:1. Portanto, a inclusão de proteínas do soro pela ultrafiltração não inibiu, como esperado, a ação proteolítica do coagulante. Esse resultado está provavelmente relacionado ao alto teor de umidade dos queijos obtidos neste experimento. Para a faixa de FC estudada, os efeitos negativos associados ao alto teor de umidade dos queijos (como aumento da intensidade de glicólise e proteólise e maior suscetibilidade ao crescimento de microrganismos contaminantes) predominaram sobre as potenciais vantagens tecnológicas do uso da técnica de ultrafiltração, o que resulta na diminuição da vida útil destes queijos.

\section{5- REFERÊNCIAS BIBLIOGRÁFICAS}

[1] ASSOCIATION OF OFFICIAL ANALYTICAL CHEMISTS. Official methods of analysis. 15. ed. Washington, 1995. $109 \mathrm{p}$.

[2] BARBANO, D.M.; LYNCH, J.M.; FLEMING, J.R. Direct and Indirect Determinationof True Protein Content of Milk by Kjeldahl Analysis: Collaborative Study. Journal of Associationof Official Analytical Chemists, v.74, p.281, 1991.

[3] BECH, A.M. Characterizing Ripening in UF-cheese. International Dairy Journal, v.3, p.329-342, 1993.

[4] CAMPOS,A.C. Efeito do Uso Combinado de Ácido Láctico com Diferentes Proporçõesde Fermento Láctico Mesófilo no Rendimento, Proteólise, Qualidade Microbiológicae Propriedades Mecânicas do Queijo Minas Frescal. Campinas, 2000, 80p. Dissertação (Mestre em Tecnologia de Alimentos)- Faculdade de Engenharia de Alimentos, Universidade Estadual de Campinas (UNICAMP).

[5] DRAKE, M. A.; SWANSON, B.G. Reduced and Low-fat Cheese Technology: Areview. Trends in Food Science and Technology, v. 6, p. 366-369, 1995.

[6] FOX, P.F. Proteolysis During Cheese Manufacture and Ripening. Journal of Dairy Science, v.72, p.1379-1400, 1989. 
[7] FURTADO, M. M.; NETO, J. P. M. L. Tecnologia de Queijos. Manual Técnico para a Produção Industrial de Queijos. São Paulo: Dipemar, 1994. Cap. 15: Minas Frescal, p. 73-75.

[8] FURTADO, M. M.; PARTRIDGE, J. A. Characterization of Nitrogen Fractions During Ripening of a Soft Cheese Made from Ultrafiltration Retentates. Journal of Dairy Science, v.71, p.2877-2884, 1988.

[9] GREEN, M. L.; ANDERSON, J. S. M.; GRIFFIN, M. C. A.; GLOVER, F. A. Chemical Characterization of Milk Concentrated by Ultrafiltration. Journal of Dairy Research, v.51, n. 2, p. 267-278, 1984.

[10] INTERNATIONAL DAIRY FEDERATION. Determination of the Total Nitrogen Content of Milk by the Kjeldahl Method. IDF-FIL, n.20, p.1-3, 1962.

[11] JENSEN, G.K.; STAPELFELDT, H. Incorporation of Whey Proteins in Cheese.Including the Use of Ultrafiltration. In: INTERNATIONAL DAIRY FEDERATION. Factors Affecting the Yield of Cheese. Brussels, 1993. Chap. 9, p. 88-105. (International Dairy Federation Special Issue, n. 9301).

[12] KONING, P.J.; BOER, R.; BOTH, P.; NOOY, P.F.C. Comparison of Proteolysis in a Low-fat Semi-hard Type of Cheese Manufactured by Standard and by Ultrafiltration Techniques. Netherlands Milk Dairy Journal, v. 35, n.1, p. 35-46, 1981.
[13] LAW, B.L. Microbiology and Biochemistry of Cheese and Fermented Milk. London: Blackie Academic \& Professional, 1997. 365 p. Chap. 6: Flavour and texture in low fat cheese, p. 207-218.

[14] LELIEVRE, J.; LAWRENCE, R.C. Manufacture of Cheese from Milk Concentrated by Ultrafiltration. Journal of Dairy Research, v.55, n.3, p.465- 478, 1988.

[15] MARSHALL, R.T., ed. 1993. Standard Methods for Examination of Dairy Products. American Publ. Health Assoc., Washington.

[16] MCGREGOR, J.U.; WHITE, C.H. Effect of Enzyme Treatment and Ultrafiltration on the Quality of Lowfat Cheddar Cheese. Journal of Dairy Science,.v. 73, n.3, p.571578, 1990.

[17] RICHARDSON, G.H. 1985. Standard Methods for Examination of Dairy Products. American Publ. Health Assoc, Washington.

[18] SHARPE, E. Lactic Acid Bacteria in the Dairy Industry. Journal of the Society of Dairy Technology, v.32, n.1, p.9-18, 1979.

[19] WOLFSCHOON, A. F.; FURTADO, M. M. Utilização do ProMilk MK II na Determinação de Proteínas no Queijo Minas Frescal. Revista do Instituto de Laticinios Cândido Tostes, v.35, n.212, p.3-6, 1980. 